\title{
ERCP is more challenging in cases of acute biliary pancreatitis than in acute cholangitis - Analysis of the Hungarian ERCP registry data
}

\author{
Dániel Pécsi ${ }^{\mathrm{a}, \mathrm{b}}$, Szilárd Gódi ${ }^{\mathrm{b}}$, Péter Hegyi ${ }^{\mathrm{a}}$, Lilla Hanák ${ }^{\mathrm{a}}$, Andrea Szentesi a , \\ István Altorjay ${ }^{\mathrm{c}}$, Tamás Bakucz ${ }^{\mathrm{d}}$, László Czakó ${ }^{\mathrm{e}}$, György Kovács ${ }^{\mathrm{c}}$, Ákos Orbán-Szilágyi ${ }^{\mathrm{d}}$, \\ Ferenc Pakodi ${ }^{\mathrm{b}}$, Árpád Patai ${ }^{\mathrm{f}}$, Zoltán Szepes ${ }^{\mathrm{e}}$, Tibor Gyökeres ${ }^{\mathrm{d}}$, Roland Fejes ${ }^{\mathrm{g}}$,

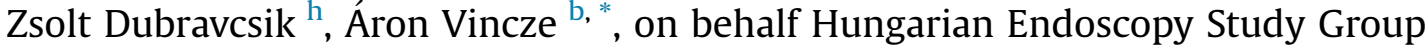 \\ a Institute for Translational Medicine, Szentágothai Research Center, Medical School, University of Pécs, Pécs, Hungary \\ ${ }^{\mathrm{b}}$ Division of Gastroenterology, First Department of Medicine, Medical School, University of Pécs, Pécs, Hungary \\ ' Second Department of Medicine, University of Debrecen, Debrecen, Hungary \\ d Department of Gastroenterology, Medical Centre Hungarian Defence Forces, Budapest, Hungary \\ e First Department of Medicine, University of Szeged, Szeged, Hungary \\ ${ }^{\mathrm{f}}$ First Department of Gastroenterology and Medicine, Markusovszky University Teaching Hospital, Szombathely, Hungary \\ ${ }^{g}$ First Department of Medicine, Szent György University Teaching Hospital of County Fejér, Székesfehérvár, Hungary \\ ${ }^{\mathrm{h}}$ Bács-Kiskun County University Teaching Hospital, Kecskemét, Hungary
}

\section{A R T I C L E I N F O}

\section{Article history:}

Received 5 August 2020

Received in revised form

24 November 2020

Accepted 27 November 2020

Available online $\mathrm{xxx}$

\section{Keywords:}

Endoscopic retrograde

cholangiopancreatography

Acute biliary pancreatitis

Acute cholangitis

Difficulty

Advanced cannulation

\begin{abstract}
A B S T R A C T
Background: Endoscopic retrograde cholangiopancreatography (ERCP) is an important therapeutic modality in acute biliary pancreatitis (ABP) cases with cholangitis or ongoing common bile duct obstruction. Theoretically, inflammation of the surrounding tissues would result in a more difficult procedure. No previous studies examined this hypothesis.

Objectives: ABP and acute cholangitis $(\mathrm{AC})$ without $\mathrm{ABP}$ cases were compared to assess difficulty of ERCP. Methods: The rate of successful biliary access, advanced cannulation method, adverse events, cannulation and fluoroscopy time were compared in 240 ABP cases and 250 AC cases without ABP. Previous papillotomy, altered gastroduodenal anatomy, and cases with biliary stricture were excluded.

Results: Significantly more pancreatic guidewire manipulation (adjusted odds ratio (aOR) 1.921 [1.241 -2.974]) and prophylactic pancreatic stent use (aOR 4.687 [2.415-9.098]) were seen in the ABP than in AC group. Average cannulation time in the ABP patients ( 248 vs. $185 \mathrm{~s} ; \mathrm{p}=0.043$ ) were longer than in $\mathrm{AC}$ cases. No difference was found between biliary cannulation and adverse events rates.

Conclusion: ERCP in ABP cases seem to be more challenging than in AC. Difficult biliary access is more frequent in the ABP cases which warrants the involvement of an experienced endoscopist.

(C) 2020 IAP and EPC. Published by Elsevier B.V. This is an open access article under the CC BY-NC-ND license (http://creativecommons.org/licenses/by-nc-nd/4.0/).
\end{abstract}

\section{Introduction}

Endoscopic retrograde cholangiopancreatography (ERCP) is an invaluable minimal invasive therapeutic modality which changed the management of several pancreato-biliary disorders [1]. In acute cholangitis (AC), early achievement of biliary drainage is associated with better outcomes, especially in severe, septic cases as stated in the new 2018 Tokyo guideline for acute cholangitis [2]. In acute biliary pancreatitis (ABP), the role of ERCP is more ambiguous,

\footnotetext{
* Corresponding author. Ifjúság u. 13., Pécs, H7624, Hungary.

E-mail address: vincze.aron@pte.hu (Á. Vincze).
}

when $\mathrm{AC}$ is also present early intervention is indicated, however, in cases with biliary obstruction only, the need for an early ERCP is questionable. The recent Dutch randomized controlled APEC trial, came to the conclusion that in patients with predicted severe acute biliary pancreatitis, early $(<24 \mathrm{~h})$ ERCP did not reduce rate of death and major complications [3].

Nevertheless, ERCP plays a significant role in the management of $A C$ and $A B P$ [4]. It is a common experience that in cases of $A B P$, duodenal and pancreatic edema might result in more difficult cannulation. There are some attempts to objectively grade the difficulty of ERCP, e.g., in the consensus-based ASGE grading system cases of acute pancreatitis get a higher, 3 points. However, no supporting data was found to this classification claim besides the 
consensus [5]. A retrospective study validated the grading system based on their center's data and found that procedural success and complications correlate well with the ASGE grades [6]. The previously widely used Schutz [7] and the newer HO.U.S.E. classification does not contain $\mathrm{ABP}$ as a factor for more complicated procedures [8].

For that reason, we intended to analyze data from the Hungarian ERCP Registry to quantify the difficulty of ABP cases compared to AC cases without pancreatitis.

\section{Methods}

\section{General cohort from the Hungarian ERCP registry}

Prospectively collected data from the Hungarian ERCP Registry were analyzed in this cohort study comparing $A B P$ and $A C$ cases. The Hungarian Endoscopy Study Group initiated the project of the Hungarian ERCP Registry in 2016 [9] and the number of participating centers growing gradually since then. Cases from 7 tertiary referral centers and 15 endoscopists were uploaded into the Registry (Suppl. Table 1). Quality indicators laid down by European and American Societies of Gastroenterology (ESGE and ASGE) were mostly met by our centers showing general good practice of ERCP $[10,11]$, only NSAID suppository usage was significantly lower, while bleeding and perforation were somewhat higher than expected (Suppl. Table 2). All participating endoscopists uploaded all ERCP cases which were done by them consecutively, no trainee participation was recorded. Recruitment period lasted from September 2016 till April 2019. A 30-day telephone follow-up was carried out to detect late adverse events. Data quality was assured by a 4-step checking system built in the Registry (1: local check from administrator, 2: endoscopist, 3: central check by chief administrator, 4: registry coordinator (ÁV)) (more information is available at https://tm-centre.org/en/registries/ercp-registry/) [9] (Suppl. Table 3). The use of different cannulation methods could be found in Suppl. Table 4.

The Hungarian ERCP Registry has been ethically approved by the Scientific and Research Ethics Committee of the Medical Research Council (TUKEB-35523/2016/EKU).

\section{Inclusion and exclusion criteria}

Subjects with previous papillotomy, altered gastroduodenal anatomy (surgery, gastro-duodenal obstruction), and biliary strictures were excluded to reach a more homogenous patient population with biliary stones or sludge as main etiology. Based on these exclusion criteria from the total of 2734 cases, finally, $240 \mathrm{ABP}$ and 250 AC cases without ABP were available for analysis (Suppl. Figure 1). Diagnosis of AC was established by the Tokyo guidelines, while the diagnosis of ABP was based on imaging and laboratory parameters, and other etiologies of pancreatitis were excluded.

\section{Definitions}

Indications of ERCP were defined in the Registry protocol according to international guidelines $[2,4,11]$. The definition of acute pancreatitis was based on the IAP/APA guidelines [4]. Presence of sludge or stone in the common bile duct and/or increase of bilirubin and/or increase of transaminase levels and/or inflammatory parameters during repeated testing in $12-24 \mathrm{~h}$ intervals were the indications of ERCP in both groups. Guidewire-assisted simple cannulation technique was first attempted at initial cannulation, in case of failure advanced cannulation methods (needle-knife precut, PGW-assisted techniques) were tried. PPS insertion was carried out only in cases of difficult biliary access, after unintentional PGW insertion. Cannulation algorithm laid down by ESGE was followed in all centers [12]. Adverse events such as bleeding, perforation, post-ERCP pancreatitis were defined as in the consensus paper from Cotton et al. [13].

\section{Analyzed dataset}

Besides the baseline, demographic data (gender, age, American Society of Anesthesiology (ASA) status), the presence of juxtapapillary diverticulum (JPD), anticoagulation/antiplatelet medication use, the rate of successful biliary access, the use of advanced cannulation methods, post-ERCP pancreatitis (PEP) prophylaxis measures (non-steroid suppositories, prophylactic pancreatic stent placement), adverse event rates (bleeding, perforation, PEP), cannulation and fluoroscopy times were compared in the two groups. This cohort study conforms with the STROBE guidelines [14].

\section{Statistical analysis}

Continuous measures are summarized and presented as means and standard deviations (SD) or as median and interquartile ranges (IQR). Categorical data are presented as observed and as percentages. To determine differences between continuous parameters, depending on the distribution of the data, we used the independent Student's t-test or the Mann-Whitney $U$ test for two groups. We used the Chi-square test or Fisher's exact test to analyze the relations between the factors under examination and odds ratios were also calculated. Binary logistic regression with stepwise forward elimination was used to observe independent prognostic factors from the followings: age, gender, study groups (ABP vS AC), JPD and ASA score for the main outcomes (advanced cannulation rate, pancreatic cannulation, pancreatic stent placement) where significant differences were detected, and enough data was available. All analyses were performed with SPSS 25 statistical software (IBM Corporation, Armonk, NY).

We performed a sample size calculation before the study was

Table 1

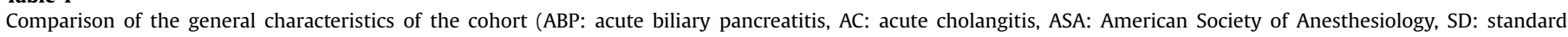
deviation).

\begin{tabular}{|c|c|c|c|}
\hline & $\mathrm{ABP}(\mathrm{n}=240)$ & $\mathrm{AC}(\mathrm{n}=250)$ & p-value \\
\hline Mean age $(S D)$ & $63.13(16.74)$ & $69.56(15.65)$ & $<0.001$ \\
\hline Sex ratio (female/all) & 0.60 & 0.50 & 0.026 \\
\hline ASA I & 80 & 52 & 0.002 \\
\hline ASA II & 130 & 140 & 0.648 \\
\hline ASA III & 23 & 54 & $<0.001$ \\
\hline ASA IV & 6 & 2 & 0.139 \\
\hline Previous anticoagulation or antiplatelet therapy & $65 / 240$ & $83 / 250$ & 0.140 \\
\hline Juxtapapillary diverticulum & $31 / 240$ & $67 / 250$ & $<\mathbf{0 . 0 0 1}$ \\
\hline
\end{tabular}


Table 2

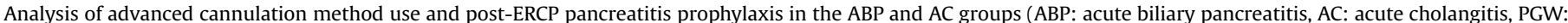

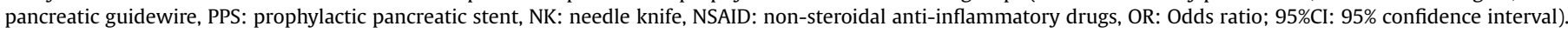

\begin{tabular}{|c|c|c|c|c|c|c|}
\hline & $\operatorname{ABP}(n=240)$ & $\mathrm{AC}(\mathrm{n}=250)$ & OR $(95 \% \mathrm{CI})$ & p-value & adjusted OR (95\%CI) & p-value \\
\hline Advanced biliary cannulation rate & $108(45.0 \%)$ & $61(24.4 \%)$ & $2.54(1.73,3.72)$ & $<\mathbf{0 . 0 0 1}$ & $2.388(1.691-3.522)$ & $<0.001$ \\
\hline \multirow[t]{3}{*}{ Pancreatic cannulation $1 \mathrm{x}$ multiple } & $75(31.3 \%)$ & $43(17.2 \%)$ & $2.19(1.43,3.35)$ & $<0.001$ & $1.921(1.241-2.974)$ & 0.003 \\
\hline & $43(17.9 \%)$ & $19(7.6 \%)$ & $2.54(1.43,4.50)$ & 0.001 & & \\
\hline & $32(13.3 \%)$ & $24(9.6 \%)$ & $1.45(0.83,2.54)$ & 0.194 & & \\
\hline Sequential advanced methods needed & $30 / 108(27.8 \%)$ & $13 / 61(21.3 \%)$ & $1.42(0.68,2.99)$ & 0.354 & - & - \\
\hline Primary PGW/PPS-assisted advanced method used & $36 / 108(33.3 \%)$ & $14 / 61(22.9 \%)$ & $1.68(0.82,3.44)$ & 0.156 & - & - \\
\hline Primary NK advanced method used & $72 / 108(66.7 \%)$ & $47 / 61(77.0 \%)$ & $0.60(0.29,1.22)$ & 0.156 & - & - \\
\hline PPS inserted & $47(19.6 \%)$ & $12(4.8 \%)$ & $4.83(2.49,9.36)$ & $<\mathbf{0 . 0 0 1}$ & $4.687(2.415-9.098)$ & $<\mathbf{0 . 0 0 1}$ \\
\hline NSAID suppository use & $161(67.1 \%)$ & $155(62.0 \%)$ & $1.25(0.86,1.81)$ & 0.240 & - & - \\
\hline
\end{tabular}

Table 3

Comparison of adverse event rates in the ABP and AC groups (ABP: acute biliary pancreatitis, AC: acute cholangitis, N.A.: not applicable).

\begin{tabular}{llll}
\hline & $\mathrm{ABP}(240)$ & $\mathrm{AC}(250)$ & $\mathrm{p}$-value \\
\hline Intraprocedural, immediate bleeding & $23(9.6 \%)$ & $18(7.2 \%)$ & 0.341 \\
Late, clinically significant bleeding & $0(0.0 \%)$ & $2(0.8 \%)$ & 0.499 \\
Conservatively managed perforation & $2(0.8 \%)$ & $3(1.2 \%)$ & 1.000 \\
Cholecystitis & $3(1.3 \%)$ & $4(1.6 \%)$ & 1.000 \\
Post-ERCP pancreatitis & N.A. & $3(1.2 \%)$ & N.A. \\
\hline
\end{tabular}

initiated which was based on the assumption that in the control group (AC) $20 \%$ advanced cannulation rate could be expected and we estimated the effect of ABP could increase the rate of advanced cannulation by an odds ratio of 2 (33\%). Calculating by a two-sided significance level of 95\%, $80 \%$ power, and the assumption mentioned above, at least $187 \mathrm{ABP}$ and $187 \mathrm{AC}$ cases would be needed to detect a significant difference. OpenEpi online calculator was used to estimate the sample size (https://www.openepi.com/ SampleSize/SSCohort.htm).

Sensitivity analyses were carried out excluding ABP cases with questionable indication of ERCP, i.e. cases where stone or sludge were not detected during the ERCP to reinforce the robustness of the results.

\section{Results}

General characteristics of the cohort

AC patients were significantly older than ABP patients (69.6 vs. 63.1 years, $\mathrm{p}<0.001$ ), while more women were in the ABP group (60\% vs. 50\%) (Table 1; Suppl. Figure 2). A higher proportion of ASA I patients was in the younger ABP group, while more ASA III patients were in the older AC group. No significant difference was found in the anticoagulation and antiplatelet usage between the two groups. Interestingly, more juxtapapillary diverticula were observed in AC patients $(26.8 \%$ vs. $12.9 \%, \mathrm{p}<0.001)$ (Table 1$)$.

\section{Findings of ERCP}

Normal cholangiogram was observed more frequently in ABP than in AC cases $(20.0 \%$ vs. $12.3 \%, p=0.026)$. Dilated common bile duct (CBD) without stone or sludge was found during ERCP in a higher proportion of ABP patients, compared to AC patients (22.6\% vs. $12.8 \%$, respectively, $\mathrm{p}=0.005$ ). The prevalence of biliary sludge without stones and small CBD stones $(\leq 10 \mathrm{~mm})$ were not significantly different in ABP and AC group (14.3\% vs. 9.1\% ( $\mathrm{p}=0.073)$ and $39.1 \%$ vs. $46.9 \%$ ( $p=0.088)$, respectively). Large CBD stones were present more commonly in AC patients ( $3.9 \%$ vs. $18.9 \%, \mathrm{p}<0.001$ ). Expectedly, purulent bile was more frequently found in $\mathrm{AC}$ cases than in ABP cases $(6.5 \%$ vs. $22.2 \%, \mathrm{p}<0.001)$ (Suppl. Table 5$)$. No

\section{Biliary cannulation success rate}

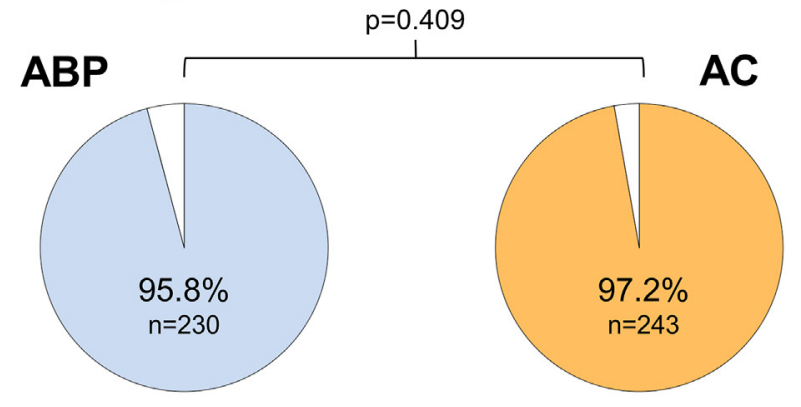

\section{Simple cannulation success rate}

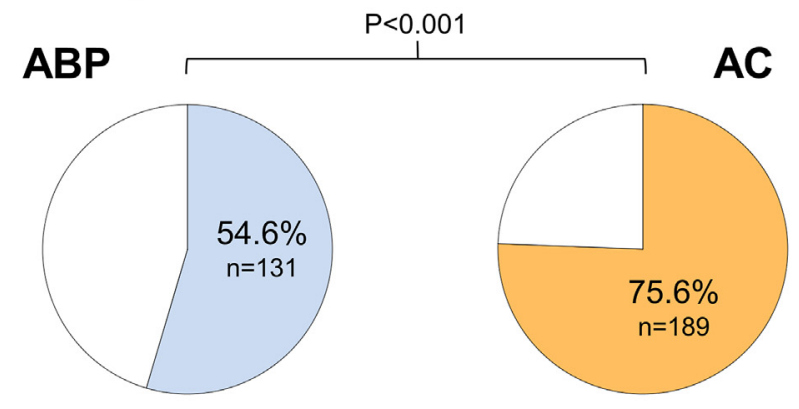

Advanced cannulation success rate

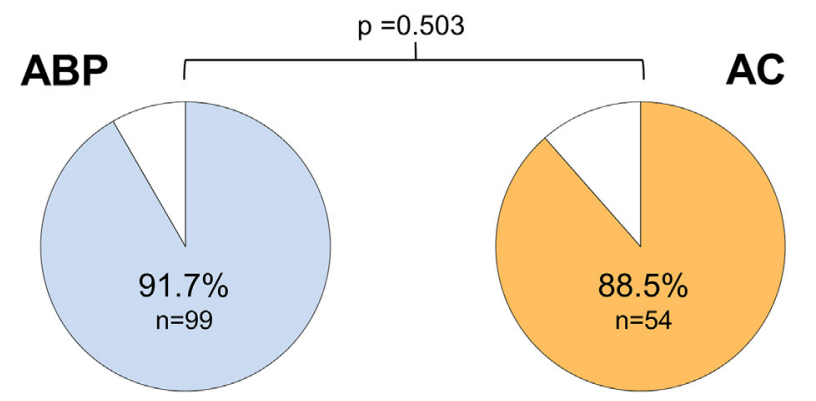

Fig. 1. Analysis of successful biliary access rate in all, simple cannulation and advanced cannulation cases (ABP: acute biliary pancreatitis, AC: acute cholangitis).

stone extraction was attempted, only a stent was inserted in 13/240 (5.4\%) in ABP vs. 14/250 (5.6\%) in AC cases, due to large stones or in patients with clopidogrel or oral anticoagulant therapy.

Biliary cannulation success rates

Successful biliary access was achieved in ABP cases in 230/240 
Cannulation time (in seconds)

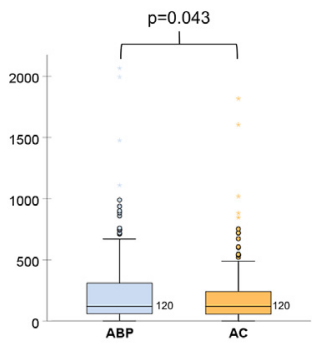

Proportion of $>5$-minute cannulation time

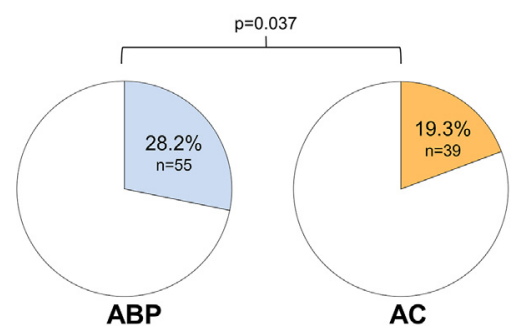

Fig. 2. Comparison of cannulation time (median, in seconds) and proportion of more than 5-min cannulation time in the ABP and AC group (ABP: acute biliary pancreatitis, AC: acute cholangitis).

(95.8\%) vs. $243 / 250$ (97.2\%) in AC cases ( $p=0.409)$ during the initial ERCP. Simple cannulation succeeded less frequently in the ABP group (54.6\% vs. $75.6 \%$; p $<0.001$ ), however, no difference was found in the success rate of advanced cannulation methods in the two groups (91.7\% vs. 88.5\%; p = 0.503) (Fig. 1).

\section{Advanced cannulation methods and post-ERCP pancreatitis prophylaxis}

Advanced cannulation methods were used in 108/240 (45.0\%) cases of ABP, while only in $61 / 250(24.4 \%)$ of AC cases ( $<<0.001)$. Multiple advanced methods were used in 13/61 in AC and 30/108 in ABP cases, respectively ( $\mathrm{p}=0.354)$. More pancreatic duct manipulations were found in the ABP group (31.3\% vs. $17.2 \%, \mathrm{p}<0.001$ ) and also more prophylactic pancreatic stents (PPS) were inserted in these patients ( $19.6 \%$ vs. $4.8 \%$; $p<0.001$ ). No difference was seen in the NSAID suppository use between the two groups (67.1\% vs. $62 \%$; $\mathrm{p}=0.240$ ) (Table 2).

Carrying out a binary logistic regression for the main outcomes (advanced cannulation rate, pancreatic cannulation, pancreatic stent placement) did not change ORs significantly by the adjustment (Table 2).

Excluding ABP cases with negative cholangiograms, the differences between the use of advanced cannulation methods (OR 2.47 [1.62-3.37], $\mathrm{p}<0.001$ ), pancreatic cannulation rate (OR 2.37 [1.52-3.70], $\mathrm{p}<0.001$ ), PPS insertion rate (OR 4.99 [2.53-9.83], $\mathrm{p}<0.001)$ remained significantly different between the two groups.

\section{Adverse event rates}

Only a low number of clinically significant bleeding ( $0 \%$ vs. $0.8 \%$ ), perforation ( $0.8 \%$ vs. $1.2 \%)$, cholecystitis ( $1.3 \%$ vs. $1.6 \%)$, immediate bleeding ( $9.6 \%$ vs. $7.2 \%$ ) were detected, and no significant difference could be detected between the groups in this regard (Table 3 ).

\section{Cannulation times}

The average biliary cannulation time was significantly longer in the ABP group (248 vs. $185 \mathrm{~s}, \mathrm{p}=0.043$ ) (Fig. 2), however, that difference could not be found when the simple (113 vs. $116 \mathrm{~s}$ ) or the advanced cannulation time (409 vs. 396 s) were separately analyzed. The number of more than 5-min cannulation was higher in the ABP patients ( $28.2 \%$ vs. $19.3 \%$; $p=0.037$ ) (Fig. 2 ), and with normal cholangiograms, the cannulation lasted longer in the ABP group ( 324 vs. $154 \mathrm{~s} ; \mathrm{p}=0.040$ ). This difference could also be seen in patients without JPD (261 vs. $158 \mathrm{~s}, \mathrm{p}=0.005$ ) (Suppl. Table 6).

\section{Fluoroscopy time}

Fluoroscopy time was longer in the AC group, when all cases (91 s vs. $107 \mathrm{~s} ; \mathrm{p}=0.009$ ) (Fig. 3), and the simple cannulation cases (91 s vs. $107 \mathrm{~s} ; \mathrm{p}=0.008$ ) were compared. When stone extraction was done in AC patients, it took significantly longer, most probably due to the higher rate of larger $(>1 \mathrm{~cm})$ stones (89 s vs. $107 \mathrm{~s}$; $\mathrm{p}=0.009$ ). In other subgroups, no differences were found (Suppl. Table 7).

\section{Discussion}

Our data support the ASGE grading of difficulty for acute biliary pancreatitis in ERCP. Several parameters suggest that ERCP is more challenging in $\mathrm{ABP}$ cases than in AC cases. We found that the rate of advanced cannulation method use and the rate of inadvertent pancreatic cannulation were higher and cannulation time was longer in $\mathrm{ABP}$ patients than in $\mathrm{AC}$ cases. This observation points to the fact that we face difficult biliary cannulation in ABP more frequently compared to AC cases, where similar pathologic changes related to the biliary tree are expected. Importantly, the cannulation success rate and the rate of adverse events were not influenced by this. We also found a higher number of cases with normal cholangiogram in the ABP group (20.0\%) compared to AC (12.3\%). In these cases, spontaneous passage of stones or sludge by the time of ERCP is one possible explanation for the initial worsening of cholestatic parameters. Additionally, this also might be due to the difficulty of diagnosing acute cholangitis when acute pancreatitis is also present, but also can be explained by the suboptimal availability of preprocedural endoscopic ultrasound evaluation in the participating Hungarian centers. ERCPs could have been avoided in these cases, cost and avoidable invasiveness should be highlighted, as a potential benefit [15]. Fluoroscopy time does not correlate with the difficulty of biliary access in our study, more likely it depends on

\section{Fluoroscopy time (in seconds)}

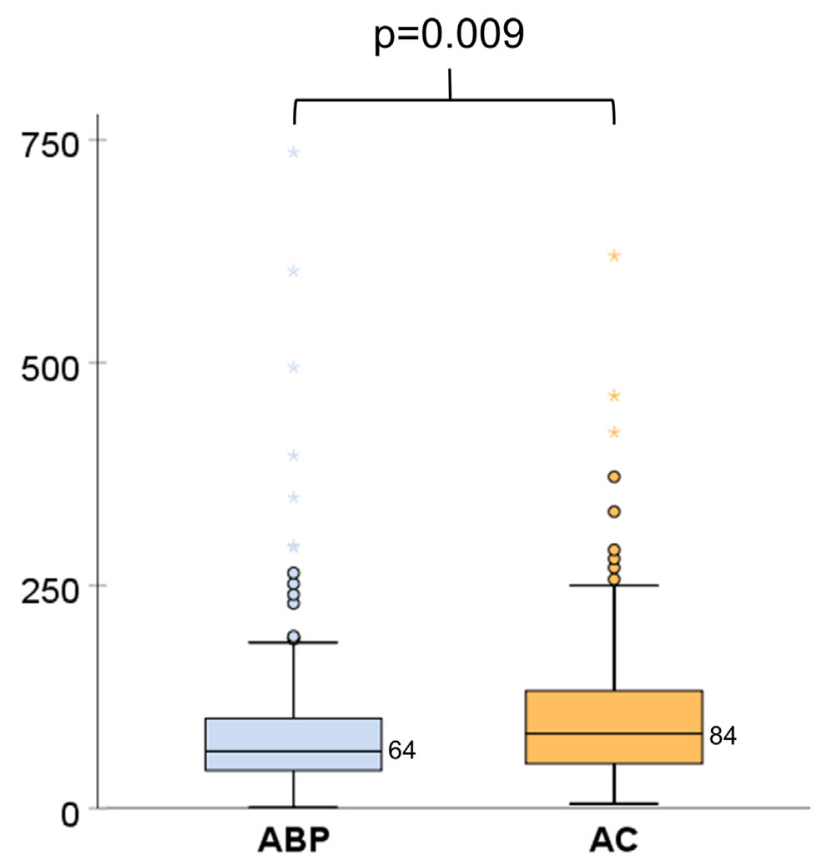

Fig. 3. Comparison of fluoroscopy times in the ABP and AC groups (median, in seconds) (ABP: acute biliary pancreatitis, AC: acute cholangitis). 
the occurrence and size of bile duct stones, since large stones were more frequently found in the AC group.

Our study has several strengths, first of all, it is a quite large, prospectively collected, nationwide dataset from several centers in Hungary. Consecutively collected ABP and AC cases were available in almost equal numbers with good data quality, detailed data set, and in an appropriate sample size. Secondly, our registry system has a built-in quality assurance program that could limit false data entry and underreporting. Multivariable statistics also confirmed the robustness of our findings.

There are some limitations to our study. Post hoc questions raised in a prospective registry database might result in confounding effects. All cases come from high-volume centers and endoscopists, and case distribution is varied among centers that hinder generalizability (Suppl. Table 1). The inherent biases of observational studies and retrospective designs e.g., selection bias should be noted in our study as well. There were some differences between the two groups, firstly, AC patients were older, and had more comorbidities (more ASA III patients). Secondly, more juxtapapillary diverticula were found in the $A C$ group. For this reason, binary logistic regression model was used to adjust for these differences. Thirdly, the differentiation of AC cases in the ABP group could not have been done due to the lack of reliable guidelines or tools to confirm the presence of cholangitis in ABP [16]. We were curious about the additional worsening effect of $A B P$ on $A C$ and non- $A C$ cases, but we could not reliably separately analyze $\mathrm{AC}+\mathrm{ABP}$ and $\mathrm{ABP}$ cases without AC. These factors could somewhat limit our analysis.

Based on our data, ABP cases should be handled by more experienced endoscopists who are familiar with a wide range of cannulation techniques, pancreatic guidewire assisted (double guidewire and transpancreatic sphincterotomy), as well as needle knife precut techniques $[12,17,18]$. To lower the worsening effect of inducing more pancreatic edema, the insertion of a prophylactic pancreas stent might potentially improve disease course [19].

Taken together, the grade 3 difficulty classification by ASGE seems to be justified for the ABP cases, and these patients should not be left to the less experienced endoscopists. Additionally, determining the appropriate indication of ERCP is vital in ABP patients. Hence, we would like to emphasize the need for the broader application of less invasive diagnostic tools (e.g., endoscopic ultrasound) in this patient population to decrease the number of unnecessary ERCPs.

\section{Funding}

This project was supported by „GINOP-2.3.2-15-2016-00048 STAY ALIVE" and "EFOP-3.6.2-16-2017-0006 - LIVE LONGER" grants which are co-financed by the European Union (European Regional Development Fund) within the framework of Program Széchenyi 2020.

\section{Declaration of competing interest}

The authors declare that they have no conflict of interest.

\section{Acknowledgement}

A different version of the abstract is published as a conference abstract at https://onlinelibrary.wiley.com/doi/full/10.1111/den. 13598. This full article is not published nor is under publication elsewhere.

\section{Appendix A. Supplementary data}

Supplementary data to this article can be found online at https://doi.org/10.1016/j.pan.2020.11.025.

\section{References}

[1] Cotton PB, Leung JW. ERCP: the fundamentals. John Wiley \& Sons; 2014.

[2] Miura F, Okamoto K, Takada T, Strasberg SM, Asbun HJ, Pitt HA, et al. Tokyo Guidelines 2018: initial management of acute biliary infection and flowchart for acute cholangitis. J Hepato-Biliary-Pancreatic Sci 2018;25:31-40.

[3] Schepers NJ, Hallensleben ND, Besselink MG, Anten M-PG, Bollen TL, Da Costa DW, et al. Urgent endoscopic retrograde cholangiopancreatography with sphincterotomy versus conservative treatment in predicted severe acute gallstone pancreatitis (APEC): a multicentre randomised controlled trial. Lancet 2020;396:167-76.

[4] Working Group Iap/APA Acute Pancreatitis Guidelines. IAP/APA evidencebased guidelines for the management of acute pancreatitis. Pancreatol Off J Int Assoc Pancreatol IAP Al 2013;13:e1-15.

[5] Cotton PB, Eisen G, Romagnuolo J, Vargo J, Baron T, Tarnasky P, et al. Grading the complexity of endoscopic procedures: results of an ASGE working party. Gastrointest Endosc 2011;73:868-74.

[6] Sahar N, La Selva D, Gluck M, Gan SI, Irani S, Larsen M, et al. The ASGE grading system for ERCP can predict success and complication rates in a tertiary referral hospital. Surg Endosc 2019;33:448-53.

[7] Schutz SM. Grading the degree of difficulty of ERCP procedures. Gastroenterol Hepatol N 2011;7:674-6.

[8] Olsson G, Arnelo U, Swahn F, Törnqvist B, Lundell L, Enochsson L. The H.O.U.S.E. classification: a novel endoscopic retrograde cholangiopancreatography (ERCP) complexity grading scale. BMC Gastroenterol 2017;17:38.

[9] Pécsi D, Hegyi P, Szentesi A, Gódi S, Pakodi F, Vincze A. [The role of endoscopy registries in quality health care. The first data from the Hungarian Endoscopic Retrograde Cholangiopancreatography (ERCP) Registry]. Orv Hetil 2018;159: 1506-15.

[10] Domagk D, Oppong KW, Aabakken L, Czakó L, Gyökeres T, Manes G, et al Performance measures for ERCP and endoscopic ultrasound: a European society of gastrointestinal endoscopy (ESGE) quality improvement initiative. Endoscopy 2018:50:1116-27.

[11] Adler DG, Lieb JG, Cohen J, Pike IM, Park WG, Rizk MK, et al. Quality indicators for ERCP. Am J Gastroenterol 2015;110:91-101.

[12] Testoni PA, Mariani A, Aabakken L, Arvanitakis M, Bories E, Costamagna G, et al. Papillary cannulation and sphincterotomy techniques at ERCP: European society of gastrointestinal endoscopy (ESGE) clinical guideline. Endoscopy 2016;48:657-83.

[13] Cotton PB, Lehman G, Vennes J, Geenen JE, Russell RC, Meyers WC, et al. Endoscopic sphincterotomy complications and their management: an attempt at consensus. Gastrointest Endosc 1991;37:383-93.

[14] von Elm E, Altman DG, Egger M, Pocock SJ, Gøtzsche PC, Vandenbroucke JP, et al. Strengthening the Reporting of Observational Studies in Epidemiology (STROBE) statement: guidelines for reporting observational studies. BMJ 2007;335:806-8.

[15] Zaheer A, Anwar MM, Donohoe C, O’Keeffe S, Mushtaq H, Kelleher B, et al. The diagnostic accuracy of endoscopic ultrasound in suspected biliary obstruction and its impact on endoscopic retrograde cholangiopancreatography burden in real clinical practice: a consecutive analysis. Eur J Gastroenterol Hepatol 2013;25:850-7.

[16] Halász A, Pécsi D, Farkas N, Izbéki F, Gajdán L, Fejes R, et al. Outcomes and timing of endoscopic retrograde cholangiopancreatography for acute biliary pancreatitis. Dig Liver Dis Off J Ital Soc Gastroenterol Ital Assoc Study Liver 2019;51:1281-6.

[17] Pécsi D, Farkas N, Hegyi P, Balaskó M, Czimmer J, Garami A, et al. Transpancreatic sphincterotomy has a higher cannulation success rate than needleknife precut papillotomy - a meta-analysis. Endoscopy 2017;49:874-87. https://doi.org/10.1055/s-0043-111717.

[18] Sugiyama H, Tsuyuguchi T, Sakai Y, Mikata R, Yasui S, Watanabe Y, et al. Transpancreatic precut papillotomy versus double-guidewire technique in difficult biliary cannulation: prospective randomized study. Endoscopy 2018;50:33-9.

[19] Dubravcsik Z, Madácsy L, Gyökeres T, Vincze Á, Szepes Z, Hegyi P, et al. Preventive pancreatic stents in the management of acute biliary pancreatitis (PREPAST trial): pre-study protocol for a multicenter, prospective, randomized, interventional, controlled trial. Pancreatol Off J Int Assoc Pancreatol IAP Al 2015;15:115-23. 